\title{
Research and Realization of the Intelligent Automatic Programming System of the Worm Gear Grinding Machine
}

\author{
Kuibang Zhang ${ }^{1}$, Jiang $\operatorname{Han}^{1}$, Lian Xia ${ }^{1}$ \\ School of Mechanical Engineering \\ Hefei University of Technology \\ Hefei, Anhui, China, 230009
}

\author{
Qingyan Yang ${ }^{2}$ \\ College of Mechanical and Electrical Engineering \\ Anhui Jianzhu University \\ Hefei, Anhui, China, 230009 \\ E-mail: 1015271621@qq.com
}

\begin{abstract}
In order to meet the machine tool could intelligent machining for the new worm wheel gear, a parametric zero programming CNC system is developed based on the modern embedded control technology. The ARM + DSP + FPGA as CNC module hardware platform, and using VS2005 VC ++ module development CNC worm wheel grinder processing automatic programming system on the WinCE operating system. Before gear grinding only need to input certain such as the workpiece parameters, tool parameters and process parameters est. through man-machine interface, then the automatic programming software system will check and calculate these parameters, and choose the machining parameters based on process database, finally automatically generate the format NC program for the CNC worm wheel gear grinding machining.
\end{abstract}

Keywords-microprocessors; embedded CNC; worm gear grinding machine; automatic programming

\section{INTRODUCTION}

The worm gear grinding machine is a kind of gear finishing machine of high efficiency and precision and used to grind or modify cylindrical involute gears with mass production of small module gears. At present, $\mathrm{CNC}$ machine has come into an era of intelligence and been attached more intelligent technology. The technology and function could be divided into five aspects: 1. intelligent processing technology; 2. intelligent condition monitoring and maintenance technology; 3 . intelligent drive technology; 4. intelligent error compensation technology; 5. intelligent operation interface and network technology. The intelligent operation interface and network technology is used to let the machine tool have more convenient operation system [1]. In order to follow the technology development in the world, meet the user needs and reach the world advanced level, the intelligent operation interface with modern automatic programming technology of worm gear grinding machine has specially been designed instead of traditional programming with the high requirement of programming personnel and frequent occurrence of errors in programming, especially in the computation and program input by keyboard, resulting in negative effect of gear processing quality, low efficiency and long production cycle.
Automatic programming is a technology of translating the easy understanding part program to $\mathrm{CNC}$ processing code which could be identified by machine tool and the majority of programming is completed by computer. In this paper, with the analysis the automatic programming of processing gears in $\mathrm{CNC}$ worm gear grinding machine on the gear's specialization, the mathematical model of programming of gear processing on worm gear grinding machine has been built and based on the model, a NC code automatic generation technology of $\mathrm{CNC}$ worm gear grinding machine has been developed which can be described in detail as a technology of inputting special parameters of workpiece, cutting tool and processing, checking and calculating parameters, choosing optimal processing parameters from process database and generating automatically $\mathrm{NC}$ codes of the gear processing according to the code structure of the $\mathrm{CNC}$ system on warm gear grinding machine.

\section{THE RESEARCH OF MATHEMATIC MODEL AND ALGORITHM OF} AUTOMATIC PROGRAMMING SYSTEM

\section{A. Grinding trajectory analysis}

The principle of grinding is continuous generating meshing on warm gear grinding machine and the grinding methods of displacement or several times reciprocation are both high efficient and precision processing methods. Several times reciprocation is the most common grinding method with the grinding wheel's movement in the order: (1) $\rightarrow$ (2) $\rightarrow$ (3) $\rightarrow$ (4) as shown in figure 1 . In the first step, grinding wheel moves to the reference zero point (1) $\left(\mathrm{X}_{1}, \mathrm{Z}_{1}\right)$ from the machine zero point and rotate the grinding wheel and workpiece; the second step is to move the cutting tool to the tool setting point (2), namely the initial point $\left(\mathrm{X}_{2}, \mathrm{Z}_{2}\right)$; thirdly, the processing has began with a certain radial feeding $\delta x$ till to the position (3) $\left(\mathrm{X}_{3}, \mathrm{Z}_{3}\right)$, and in the end in order to process gear in axial direction of workpiece, grinding wheel has worked from point (3) to point (4) $\left(\mathrm{X}_{4}, \mathrm{Z}_{4}\right)$. This is a one-time machining process and if more processes are needed, the way of circular processing with radial and axial feeding will be the proper answer. Returen the cutting tool to the safe point and then back to point $\left(\mathrm{X}_{1}, \mathrm{Z}_{1}\right)$. Until now, the whole process has 
completed. Obiviously, the coordination of the key points: $\left.\left(\mathrm{X}_{1}, \mathrm{Z}_{1}\right), \mathrm{X}_{2}, \mathrm{Z}_{2}\right),\left(\mathrm{X}_{3}, \mathrm{Z}_{3}\right),\left(\mathrm{X}_{4}, \mathrm{Z}_{4}\right)$ is very important in $\mathrm{CNC}$ programming.

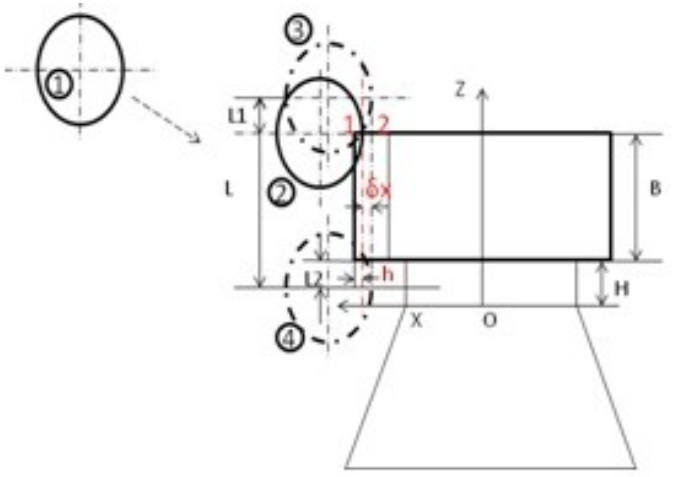

Fig. 1. Grinding trajectoty of several reciprocation

\section{B. The key coordinate points of grinding trajectory}

It is essential to get the key positions of initial, terminal and processing movement of grinding wheel. Interpolate the contour curve of the workpiece and get precisely the certain datum of every interpolation point required by the processes which are used as a basis to write command codes of CNC system. In the automatic programming system of CNC worm gear grinding process, it is necessary to ascertain the grinding trajectory that to achieve the coordination of initial, terminal and other key points. The way of grinding wheel processing from the initial to the terminal position is controlled by interpolation software of CNC system.

(1)The determination of grinding wheel installation angle

In the process of grinding gear on the warm gear grinding machine, the section of the grinding wheel in the vertical plane is a ellipse instead of a circle due to the grinding wheel installation angle $\delta$ [2]. The relaition between the size of the major axis of the ellipse and grinding wheel installation angle $\delta$ is shown in figure 2 .

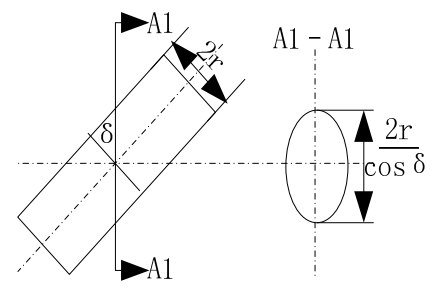

Fig. 2. The section of grinding wheel in the vertical plane A1-A1

There are some constraint relationships between grinding wheel and gear in the direction and size of spiral angle:

If the directions of $\alpha$ and $\beta$ are same, $\delta=\alpha-\beta$;

If the directions of $\alpha$ and $\beta$ are reverse, $\delta=\alpha+\beta$;

$\alpha$ is the spiral angle of gear and $\beta$ is the spiral angle of grinding wheel .

In the coordinate system, the section equation of grinding wheel is:

$$
\frac{(x-x 1)^{2}}{r^{2}}+\frac{(z-z 1)^{2} \cos ^{2} \delta}{r^{2}}=1
$$

(2) The determination of tool setting point

Because the grinding process is a finish machining and the workpiece is a gear with teeth, tool setting must be processed before machining. Setting tool is a process before grinding which adjusts the positions of grinding wheel and gear to make sure the relative position between grinding wheel and gear precise. Setting point is the initial point of grinding as point $\mathrm{h}$ shown in figure 1 .

When grinding wheel hits the left and right flanks of a tooth space, sensors can test the sonar signals which are used as a basis to generate interrupt signals in order to record the coordination of hitting the axis $\mathrm{C}$ (cylindrical surface). After hitting, the average coordination could be calculated by system and the right tool setting position and allowance distribution are also attained at the same time. The whole process is completely finished by $\mathrm{AE}$ sensors, control elements and CNC system software. Instead of the manual tool setting decided by the spark size based on the human eye observation with the inaccuracy and unsafety, this way just needs the operator move grinding wheel into the tooth space and tool setting point $(\mathrm{x} 2, \mathrm{z} 2)$ can be attained by those processes.

(3)The calculation of cutting in and out stroke of grinding wheel

In order to improve the machining efficiency, shorten the grinding path, reduce idle stroke and make sure the knife hit and overcut not occurring, the cutting in stroke must be ascertained. Cutting in stroke is the distance L1 between the grinding wheel center and gear high transverse plane at the beginning the processing and cutting out stroke is the distance L2 between the grinding center and gear low transverse plane at the end of processing as shown in figure 1.

Through the calculation and looking up gear manual, the cutting in stroke L1 and out stroke L2 could be attained and then based on the L1 and L2, the coordination of every key point can be ascertained.

\section{The movement relationship between grinding wheel and gear}

In the warm gear grinding processing, there are four kinds of movement: warm gear grinding movement $\mathrm{N}_{\mathrm{t}}(\mathrm{r} / \mathrm{min})$, workpiece index movement $\mathrm{N}_{\mathrm{i}}(\mathrm{r} / \mathrm{min})$, warm gear axial movement $V_{\mathrm{f}}(\mathrm{mn} / \mathrm{min})$ and workpiece circumferential feed movement $\mathrm{N}_{\mathrm{f}}(\mathrm{r} / \mathrm{min})$.

The relational expression between workpiece generating motion and warm gear grinding motion is: $\mathrm{N}_{\mathrm{i}}=\mathrm{K}_{\mathrm{d}} \cdot \mathrm{N}_{\mathrm{t}} / \mathrm{Z}_{\mathrm{d}}$;

The relational expression between warm gear axial feed motion and workpiece actual motion is: $\mathrm{V}_{\mathrm{f}}=\mathrm{f}_{\mathrm{a}} \cdot \mathrm{N}_{\mathrm{w}}$;

The additional movement of workpiece is: $\mathrm{N}_{\mathrm{f}}= \pm \mathrm{V}_{\mathrm{f}} / \mathrm{P}_{\mathrm{z}}$;

The spiral pitch of workpiece $\mathrm{P}_{\mathrm{z}}$ is: $\mathrm{P}_{\mathrm{z}}=\mathrm{M}_{\mathrm{n}} \cdot \pi \cdot \mathrm{Z}_{\mathrm{d}} / \sin \beta$;

The actual movement of workpiece $\mathrm{N}_{\mathrm{w}}$ is: $\mathrm{N}_{\mathrm{w}}=\mathrm{N}_{\mathrm{i}}+\mathrm{N}_{\mathrm{f}}$. 
The ascertainment of the symbols: under up-grinding, if the spiral directions of workpiece and grinding wheel are the same, the symbol will be '+', and if not, the symbol will be '-'; under down-grinding, if the spiral directions of workpiece and grinding wheel is the same, the symbol will be '-', and if not, the symbol will be '+'.

The relational expression between warm gear and workpiece actual movement is: $\mathrm{N}_{\mathrm{w}}=\mathrm{K}_{\mathrm{d}} \cdot \mathrm{N}_{\mathrm{t}} /\left[\mathrm{Z}_{\mathrm{d}}\left(1 \pm \mathrm{f}_{\mathrm{a}} / \mathrm{P}_{\mathrm{z}}\right)\right]$;

The speed of grinding wheel axial feed motion: $\mathrm{N}_{\mathrm{w}}=\mathrm{K}_{\mathrm{d}} \cdot \mathrm{N}$ $t /\left[Z_{d}\left(1 \pm f_{a} / P_{z}\right)\right]$.

In the equation, $\mathrm{N}_{\mathrm{t}}(\mathrm{r} / \mathrm{min})$ is the grinding wheel cutting movement, $\mathrm{N}_{\mathrm{i}}(\mathrm{r} / \mathrm{min})$ is generation motion of workpiece, $\mathrm{V}_{\mathrm{f}}(\mathrm{mm} / \mathrm{min})$ is the grinding wheel axial feed motion, $\mathrm{N}_{\mathrm{f}}(\mathrm{r} / \mathrm{min})$ is additional movement of workpiece, $\mathrm{N}_{\mathrm{w}}(\mathrm{r} / \mathrm{min})$ is the actual rotate speed of workpiece, $K_{d}$ is the number of threads, $Z_{d}$ is the number of teeth of workpiece, $f_{a}(\mathrm{~mm} / \mathrm{r})$ the grinding wheel feed per rotation of workpiece, $M_{n}$ the normal module of workpiece and $\beta$ is spiral angle of workpiece.

\section{Automatic dressing of grinding wheel}

In order to improve the surface accuracy in grinding and reach the desired processing requirement, the grinding wheel must be dressed at a proper time in warm gear grinding process with restoring the grinding wheel surface granularity and the principle of dressing is shown in figure 3:

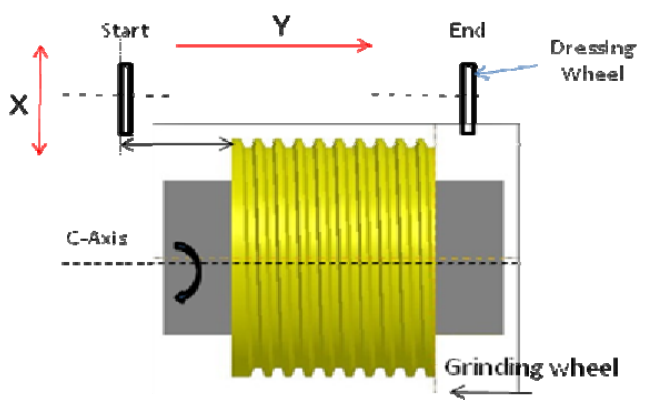

Fig. 3. The principle of dressing grinding wheel

As shown in the figure, there, in the dressing processing interface, should be set up initial coordination in $\mathrm{V}$ direction of dressing wheel, dressing feed value in $U$ direction of dressing wheel and the terminal coordination of dressing processing. The number of dressing grinding wheel should be ascertained properly. If the number of teeth of grinding wheel is less than 100, in terminal circle of grinding the dressing processe is not neceessay and in the inital grinding process, the dressing is also not needed due to the sharpeness of grinding wheel in the finish machining avoiding the big discrimination with the following teeth. If the number of teeth is more than 100, dressing grinding wheel is probably appropriate.

\section{THE CONSTRUCTION OF HARDWARE AND SOFTWARE BASED ON ARM+DSP+FPGA}

\section{A. The construction of hardware platform of CNC system}

New technology is essential to realize the complex mechanical motion and produce new $\mathrm{CNC}$ machine tool. Along with the development of modern digital technology, especially, the development of embedded system [3-4] called 'post-pc era' has made a new generation of CNC system which also be called the 'brain' of machine tool. The hardware and software are both indispensable in CNC system [5]. According to the design principle of embedded system and the requirement of the movement of warm gear grinding process, the hardware platform of automatic programming system in CNC warm gear grinding is an embedded platform based on $\mathrm{ARM}+\mathrm{DSP}+\mathrm{FPGA}$. As shown in figure 4, ARM is mainly complete the man-machine interface function of system, including user information input, storage and display and automatic programming. The work of DSP is essentially to do the complicated calculation and real-time control, such as interpolation and position control and the powerful function of data processing is used to realize high processing speed, control performance and machining accuracy. The main hardware-function modules are program memory, data memory, keyboard control, motor control, hand wheel input and so on. It is more convenient and flexible to design software with the designation of operation interface and motion control separately on ARM and DSP. The data exchange between ARM and DSP is realized by HPI and the interface logic of HPI is realized by CPLD to coordinate communication between systematic proscenium and background.

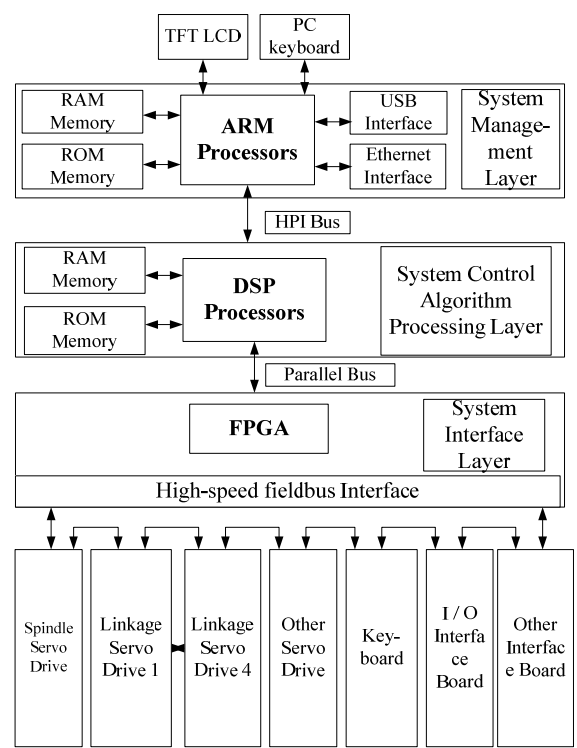

Fig. 4. The hardware construction of automatic programming of warm gear grinding process

\section{B. CNC system software}

Due to the function of ARM is mainly to complete the system human-computer interface including user information input, storage and display and automatic programming, the 
parameterized automatic programming of $\mathrm{CNC}$ gear grinding is processing on upper layer ARM. The relevant information could be transmitted to a remote server through network to realize remote monitoring diagnosis by ARM embedded with WinCE system. The development tool is $\mathrm{VC}++$ module in vs2005 and $\mathrm{VC}++$ is a typical Object-Oriented Language specially integrated MFC library encapsulated with a large number of $\mathrm{C}++$ libraries of Windows API. Programming using MFC is much according with object-oriented ideas and the application programs built by wizard could hide many details of program design, like message management.

\section{PARAMETERIZED AUTOMATIC PROGRAMMING OF CNC WARM GEAR GRINDING BASED ON ARM+DSP+FPGA SYSTEM}

\section{A. Automatic programming principle}

The principle of zero-programming technology of the special $\mathrm{CNC}$ system on warm gear grinding machine is shown in figure 5 and based on human-computer interface, the settings of gear types (such as spur gear, helical gear, small taper gear and drum gear), special programming parameters of different gears (for instance, number of teeth, normal module, spiral angle, pressure angle and gear width), the installation parameters of grinding wheel and gear and the parameters of dressing wheel could be input to the system to generate automatic processing cycle (like cycle count, cutting method, feed rate and cutting speed) and the processing cycle of grinding dressing with the support of process database. Of course, these technological parameters also can be manual input. The controls parameters are calculated by the formulas in operational library with the module of parameter processing so that the grinding wheel trajectory could be determined. Then use the post processing module to generate automatically $\mathrm{NC}$ codes and the dynamic simulation will be used to verify the correctness of the codes. The development processes are presented below:

(1) The human-computer interface has designed using the $\mathrm{VC}++$ module of vs2005 after the analysis of the kinematic relation between warm gear and workpiece. Human-computer interface is the link of human-computer interaction and should be designed with the interactive and convenient properties. The system software will automatically generate NC codes with the relevant parameters input by operator.

(2) After system is powered on, the initial page will be showed as position page set which is the main interface of processing. Position interface will display all kinds of information in real time such as coordination information, process data, machine state, alarm message, processing program, time and workpiece information. Thus it must sweep the states of all kinds of variable input in the buffer and display on the interface.

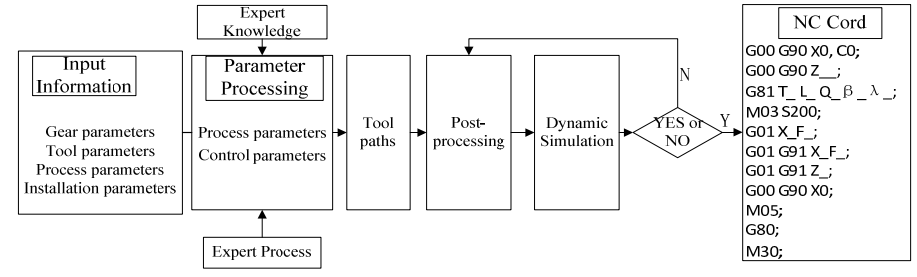

Fig. 5. Automatic programming principle of parameterized processing in warm gear grinding

(3) The communication interface between upper layer (ARM) and under layer (DSP) is HPI in the automatic programming system of CNC warm gear grinding processing. HPI is a parallel communication port between DSP and host computer, and is also an important communication interface to construct a master-slave system and realize communication between the host and slave [7-8]. Upper layer ARM can operate the data in under layer DSP through HPI and the operation is virtually in the buffer of DSP.

\section{B. The design of technic database}

The database development of warm gear grinding machine has used the SQLite as the embedded data management software based on ARM EP93115 with the good portability and less occupied space. Compared with other embedded databases, SQLite has lager advantage of performance, price and development difficulty.

Based on the parameters of workpiece, cutting tool and processing input by user, the background will invoke the technological parameters in technic database to automatically generate the processing program of warm gear grinding and, in addition, the database has to manage all kinds of information, including query, modifying, deleting and saving. The construction of function module is shown in figure 6 .

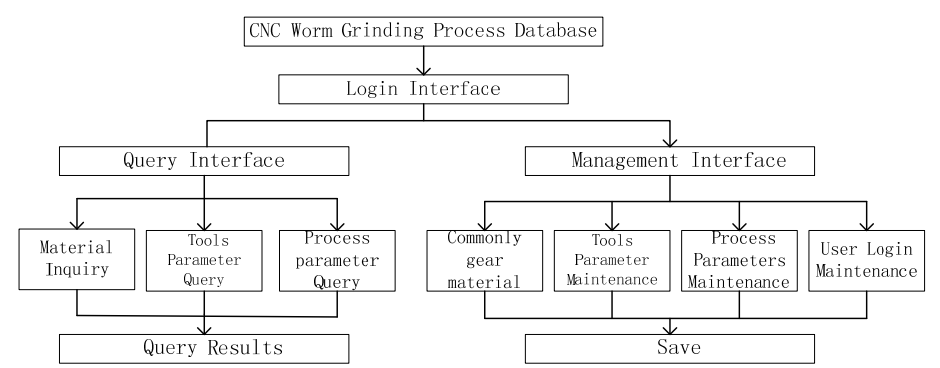

Fig. 6. The function module consturcion of technic database of warm gear grinding process.

\section{The design of human-computer interface}

As metioned above in this paper, human-computer interface provides the convenient opeartion to user embodying the friendly human-computer interaction. In the design of human-computer interface, the interface program should include several primary interfaces of CNC system: state display interface, grinding wheel parameters setting interface, workpiece parameters interface, processing parameters interface and so on. 
The figure 7 and 8 are main and grinding wheel parameter setting interface of the warm gear grining processing. As space is limited, the other setting interfaces, such as workpiece parameters, technological parameters and dressing processing parameters, will no longer be introduced one by one.

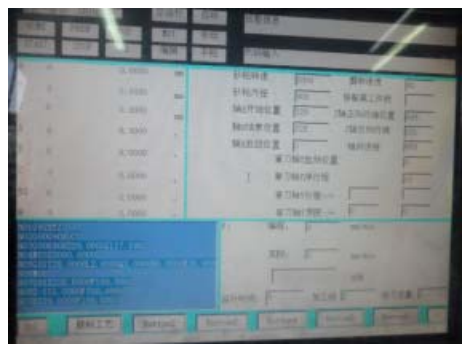

Fig. 7. State display interface.

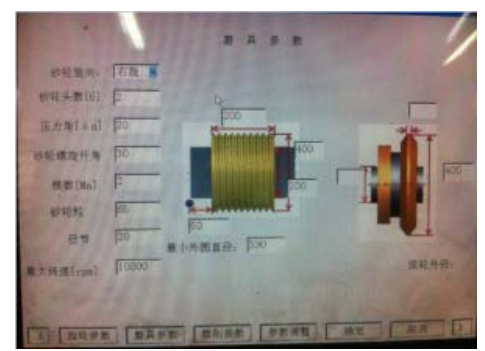

Fig. 8. grinding wheel parameters setting interface

\section{CONCLUSION}

Using the automatic programming system can shorten gear production cycle time and improve the utilization rate of $\mathrm{CNC}$ warm gear grinding machine without writing $\mathrm{NC}$ codes. In the system, the NC codes will be automatically generated only by inputting parameters of workpiece, grinding wheel, technology and other neccessary datas using the humancomputer interface instead of the complicated numeric calculation. The user requirement of the software is not so high and using the system can reduce the cost of production by shortening programming time, improving processing efficiency and no software charfe. In the system, the parameters could be verified and calculated to avoid the errors of manual programming.

\section{Acknowledgment}

The authors would like to thank the Hefei University of Technology Doctoral Fund Project, No. JZ2015HGBZ0101, and the Foundation of Hefei Universtiy Technology, No. JZ2016HGTA0697, also thank the National Natural Science Foundation of China, No. 51575154, for supporting this research under Grant.

\section{References}

[1]Sun Jiaming. Research on the intelligence technology of NC machine [J]. The world manufacturing technology and equipment market, 2012(4).

[2]Hu Chibing, Tan Weiming, Hou Qizhen. The key technology in CNC gear machining [J]. Journal of Gansu University of Technology, 1997(2).

[3]Richard A Sevenich . An Introduction tO Embedded Linux Development[J]. Linux Journal, 2004

[4]Yao Xizhong. Analysis and research of embedded system and its developmenttrend $[\mathrm{J}]$. Science and technology information, 2009

[5]Chen Wenzhi. Theory and practice of the development of embedded system [M]. Beijing: Tsinghua University press, 2005

[6]Suh, S., Kang, S., Chung, D., and Stroud, I. (2008). Theory and Design of CNC Systems, Springer, London.

[7]Liu Qiao , Mu Sien. The communication between ARM and DSP core implementation based on HPI [J]. Electronic communication technology, 2011(1).

[8]Wu Yiqi , Wu Jianping. Design of HPI and PC parallel port communication interface DSP [J]. China Testing Technology , 2007(5).

[9]Ning Keqing. DSP HPI port and ARM9 bus interface design WINCEimplementation [J]. Information system engineering, 2008(5) 